\title{
Back analysis of pile and anchor retaining structure based on BOTDA distributed optical fiber sensing technology
}

\author{
Xin Wang ${ }^{1}$, Xie Hui Luo $^{2}$, Wan Xue Long ${ }^{3}$, Bo Jiang ${ }^{3}$ \\ ${ }^{1}$ Guiyang Urban Rail Transit Group CO.LTD, Guiyang, 550081; \\ ${ }^{2}$ Guiyang Metro Real Estate Co Ltd,Guiyang,550081; \\ ${ }^{3}$ Guizhou Transportation Planning Survey and Design Academe CO.,LTD., Guiyang, 550001
}

\begin{abstract}
In order to understand the deformation law and internal force distribution characteristics of the pile-anchor retaining structure in deep foundation pit engineering, the stress of the pile-anchor retaining system in the process of foundation pit excavation was tested by using the distributed optical fiber sensing technology of BOTDA. It uses the supporting pile cloth to set up the strain cable to collect the strain from the excavation process to the stability of the foundation pit, which analyzes the stress and internal force distribution. The results show that the overall deformation of the foundation pit is small and in a stable state. It uses the monitoring strain energy to truly reflect the distribution and transmission law of the pile internal force. It is shown that the bending moment is the maximum at the action position of the anchor cable on the pile anchor structure and $2.5 \mathrm{~m}$ below the bottom of the pit. The design needs to reinforce the construction of such locations. At the same time, the distribution form of earth pressure calculated in reverse is different from the conventional one. When there are multiple rows of prestressed anchor cables, the earth pressure applied on the support is less than the calculated value of classical earth pressure theory. This pile anchor structure design theory and engineering application has reference value.
\end{abstract}

\section{Introduction}

Urban construction and all kinds of underground construction have developed rapidly in scale and quantity. Exploiting underground space has become a trend of urban development. Foundation pit near construction, foundation pit disease and safety accidents also occur frequently. There are also many prevention and control methods for foundation pit, among which the pile-anchor retaining structure is widely used in foundation pit engineering due to its particularity.

The pile-anchor supporting structure is composed of single pile and anchor cable. Compared with single pile, its deformation control ability is strong and construction is more convenient. It can effectively solve the engineering problems such as deep foundation pit, high cantilever and strict deformation requirements. However, the force calculation is complex ${ }^{[1]}$, and the parameters involved in the calculation, such as geotechnical parameters, earth pressure distribution, and the location of potential slippery surface, are uncertain. When the structure is calculated, it often refers to the experience and selects a certain form to calculate the earth pressure, which will inevitably deviate from the actual situation of the project and affect the design.

This paper considers the advantages of BOTDA distributed optical fiber sensing technology ${ }^{[2-6]}$, such as high accuracy, long life, distribution, strong anti-interference ability, corrosion resistance, small data acquisition interval and so on.It is proposed to analyze the stress mechanism of the pile-anchor retaining structure by using the micro-strain of the supporting pile at different depths during the excavation process ${ }^{[7]}$. This method can avoid the influence factors such as the uncertainty of rock and soil parameters involved in the design calculation. It can truly reflect the deformation law and internal force distribution of pile anchor structure in foundation pit supporting ${ }^{[8]}$. This consideration accords with engineering practice and provides engineering application experience for the design and construction of pile-anchor supporting structure.

\section{Engineering Application Examples}

\subsection{Project Profile}

This project is a deep foundation pit project in Guiyang, Guizhou Province. The foundation pit is about $440 \mathrm{~m}$ long. About $60 \mathrm{~m}$ wide. The excavation depth is approximately $9.5 \mathrm{~m}$ to $12 \mathrm{~m}$. The south side of the foundation pit is close to Metro Line 1, and the minimum distance between the foundation pit boundary and the viaduct of Metro Line 1 (as shown in Figure 1) is $6 \mathrm{~m}$. Pile anchor supporting structure is set on the edge of foundation pit. Its pile length is $15 \mathrm{~m}$. The row spacing is 
$2.5 \mathrm{~m}$. Three rows of anchor cables were laid along the pile body with an interval of $2.3 \mathrm{~m}$. The first row of anchor cable is $22 \mathrm{~m}$ long. The second row is $18 \mathrm{~m}$ and the third row is $14 \mathrm{~m}$. The prestress applied is $500 \mathrm{kN}$.According to the drilling Revelations, the overlying soil of the site mainly consists of Quaternary miscellaneous fill $\left(\mathrm{Q}^{\mathrm{ml}}\right)$ and residual slope deposit red clay $\left(\mathrm{Q}^{\mathrm{el}+\mathrm{dl}}\right)$. The thickness is 11 meters to 16 meters. The underlying bedrock is dark gray to gray, thin to medium thick limestone of the Daye Formation $\left(T_{1} d\right)$ of the Lower Triassic, which is partly argillaceous.

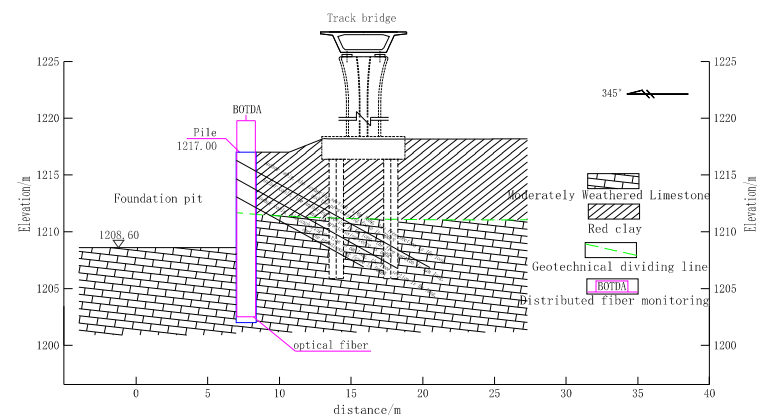

Fig 1 sectional view of pile and anchor supporting structure on the south side of foundation pit

In order to accurately understand the stress characteristics of foundation pit excavation, foundation pit topography and geomorphology, engineering geology, hydrogeology conditions, it uses distributed optical fiber sensing technology to monitor the stress and strain field of foundation pit. The monitored supporting pile parameters are shown in Table 1.

Table 1 Parameter values of supporting pile

\begin{tabular}{ccccc}
\hline $\begin{array}{c}\text { Radius of } \\
\text { cross section } \\
/ \mathrm{m}\end{array}$ & $\begin{array}{c}\text { elasticity } \\
\text { modulus } \\
/ \mathrm{GPa}\end{array}$ & $\begin{array}{c}\text { inertial } \\
\text { matrix } \\
/ \mathrm{m}^{4}\end{array}$ & $\begin{array}{c}\text { The length } \\
\text { of the pile } \\
/ \mathrm{m}\end{array}$ & $\begin{array}{c}\text { Cantilever } \\
\text { long } / \mathrm{m}\end{array}$ \\
\hline 0.7 & 30 & 0.188 & 15 & 8.5
\end{tabular}

\subsection{Optical fiber monitoring of circular retaining pile}

Fig. 2 is the layout of optical cable in the supporting pile. The cable is embedded with U1 circuit in the pile. It is bound to the main reinforcement on the soil-facing side and the soil-back side of the supporting pile in the direction of lateral earth pressure.U1 loop is connected in series with optical fiber modulation and demodulator.

The thickness of the concrete protective layer of the supporting pile is $5 \mathrm{~cm}$, and the radius of the steel cage is $65 \mathrm{~cm}$. The optical fiber spacing $\triangle \mathrm{x}$ on the symmetrical main reinforcement at the front and rear of the pile is $130 \mathrm{~cm}$. The effective testing range is $0.5 \mathrm{~m}$ to $14 \mathrm{~m}$ from the pile top. The strain cable and the supporting pile are fully coupled and deformed harmoniously after the concrete is completely condensed.

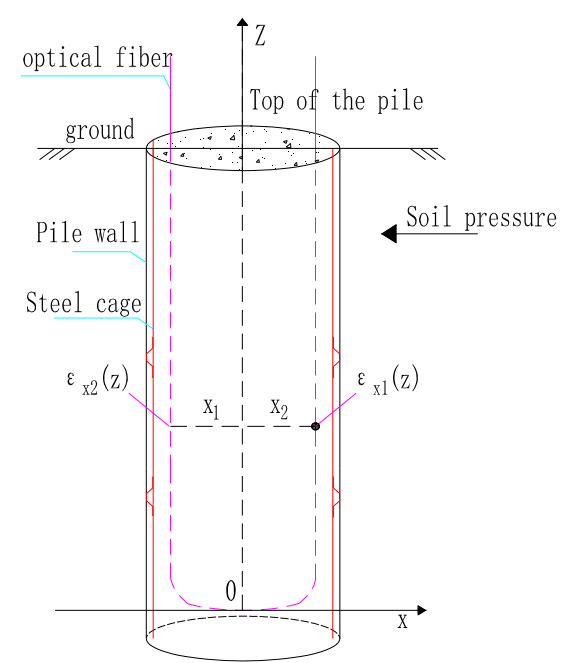

Fig.2 Fiber optic cable layout in supporting pile

The sensing cable on the anti-slide pile in the geotechnical body is less affected by temperature. It does not need to be temperature compensated ${ }^{[5]}$.Fiber field binding and testing are shown in Figure 3.

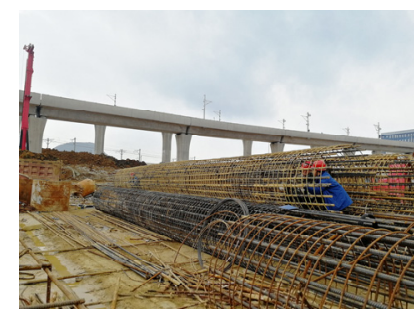

Fig. 3-a Optical Cable Layout

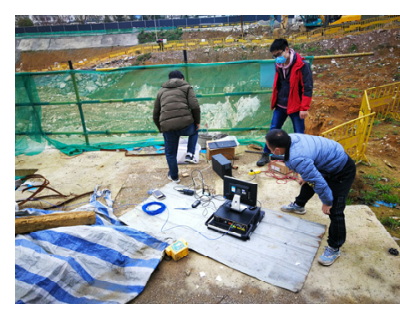

Fig 3-b Field Instrumentation Testing

\subsection{Fiber optic test strain analysis}

A total of 7 effective strain data (see Fig. 4) were obtained after the pile anchor supporting structure of the foundation pit was completed by December 30, 2020, except for the initial value. In the excavation stage, the pile deformation and axial tensile strain are produced under the action of earth pressure. In December 2019, the initial foundation pit excavation was completed. Under the action of anchor cable, the deformation of pile top area is small. The maximum strain of piles below the foundation pit bottom is $205 \times 10^{-6}$. The slope is becoming stable.

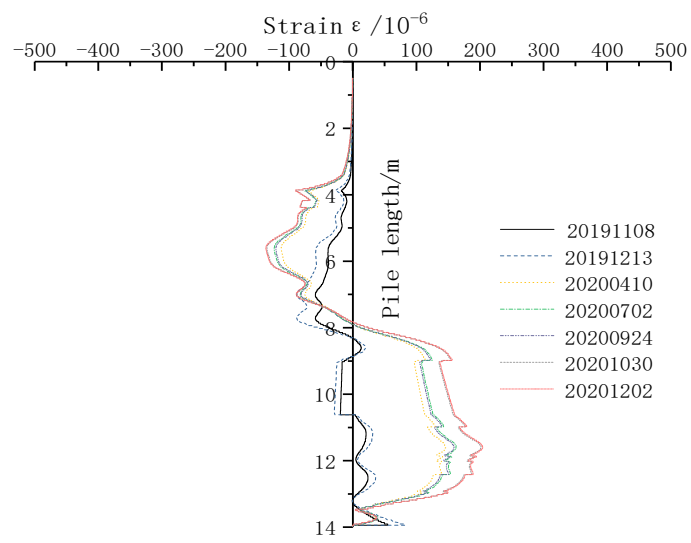

Fig.4 Strain distribution curve of supporting pile 


\section{Stress reverse analysis of pile anchor retaining structure}

\section{1 stress calculation}

It uses the theory of material mechanics to establish the function relationship between pile stress and strain ${ }^{[9]}$ to calculate and analyze the earth pressure on the pile anchor structure according to the pile strain data.

The fiber deformation is very little affected by the dead weight stress of the supporting pile. Therefore, the normal stress on any cross section of the supporting pile can be considered as the axial stress acting on the cross section ${ }^{[10]}$.According to the Euler-Bernoulli beam theory, the bending moment $\mathrm{M}(\mathrm{x})$ of the supporting pile section generated by bending under axial stress is as follows:

$$
\begin{aligned}
& \delta_{\mathrm{z}}(\mathrm{x})=\frac{M}{I_{\mathrm{y}}} \mathrm{x}=E \varepsilon_{\mathrm{z}} \\
& M(\mathrm{x})=\frac{E \varepsilon_{\mathrm{x}}}{\mathrm{x}} I_{\mathrm{y}}
\end{aligned}
$$

The shear force $\mathrm{Q}(\mathrm{x})$ and earth pressure $\mathrm{F}(\mathrm{x})$ can be used to calculate the first and second derivatives of bending moment through material mechanics.

$$
\begin{aligned}
& Q(\mathrm{x})=M(\mathrm{x})^{\prime} \\
& F(\mathrm{x})=M(\mathrm{x})^{\prime \prime}
\end{aligned}
$$

E is the elastic modulus of the supporting pile, which represents the moment of inertia of the cross section relative to the neutral axis. $\mathrm{X}$ is the distance between the monitoring point and the neutral axis. $\mathrm{Z}$ is the length of supporting pile body. $\varepsilon_{\mathrm{x} 1}(\mathrm{z})$ and $\varepsilon_{\mathrm{x} 2}(\mathrm{z})$ are the cable strain measurement values at a symmetrical position on a cross section of a single supporting pile.

\subsection{Determination of the neutral axis}

Pile pouring is affected by non-uniformity of materials and construction. The positions of optical cables at the front and back sides of the pile body are X1 and X2 from the neutral surface. The pile section is shown in Figure 5.

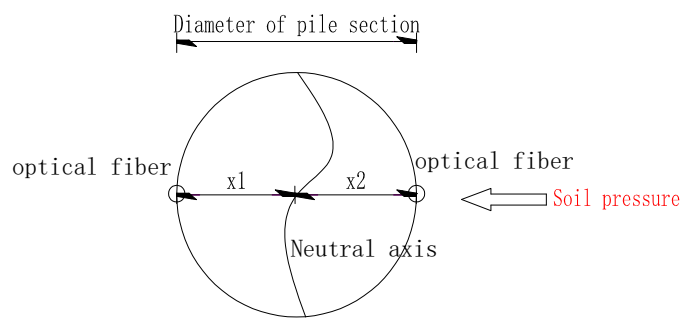

Fig5 Schematic diagram of neutral axis determination
The torque balance of the cable relative to the neutral axis is

$$
M_{1}(\mathrm{x})=\frac{E \varepsilon_{\mathrm{x}_{1}}}{\mathrm{x}_{1}} I_{\mathrm{y}}=M_{2}(\mathrm{x})=\frac{E \varepsilon_{\mathrm{x}_{2}}}{\mathrm{x}_{2}} I_{\mathrm{y}}=M(\mathrm{x})
$$

The bending moment $\mathrm{M}(\mathrm{x})$ of the supporting pile section generated by bending under axial stress can be expressed as:

$$
M(\mathrm{x})=\frac{E \varepsilon_{\mathrm{x}_{1}}-E \varepsilon_{\mathrm{x}_{2}}}{\mathrm{x}_{1}-\mathrm{x}_{2}} I_{\mathrm{y}}
$$

\subsection{Optical fiber test force back analysis}

1、Internal force distribution of pile body

According to the pile strain curve and formulas (1) to (6), it uses Matlab numerical analysis software to fit the internal force distribution of the pile-anchor retaining structure in the process of foundation pit excavation. It establishes the relationship curve between pile internal force and pile length. It is seen Figure 6 and 7 for the results.

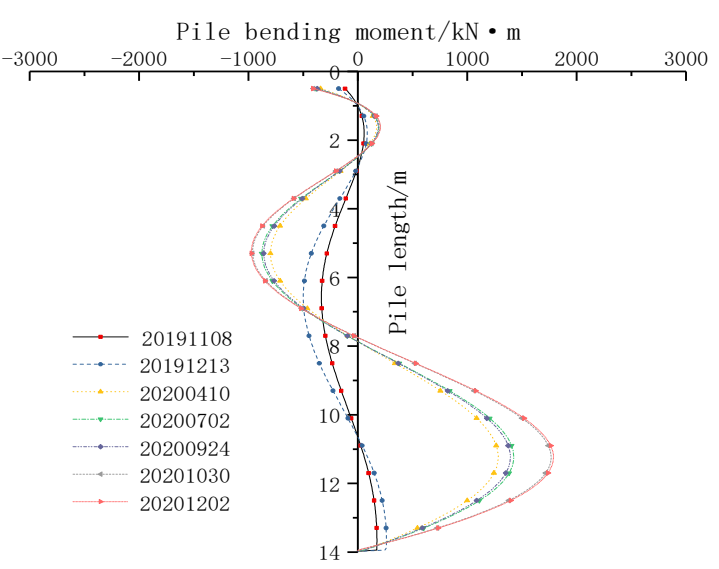

Fig6 Bending moment distribution curve of pile body measured

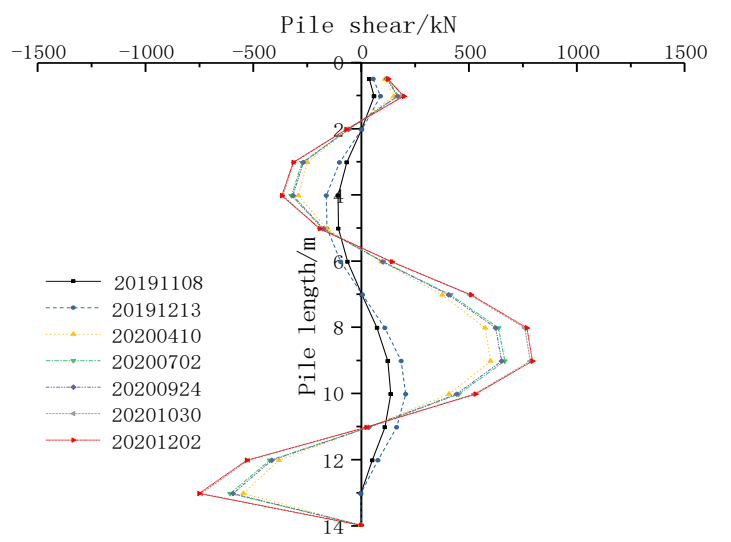

Fig7 Measured shear force distribution curve of pile body can be known from distributed optical fiber monitoring results

(1) It can be seen from the curve in Fig. 6 that the bending moment increases significantly with the excavation of the foundation pit. Under the combined 
action of earth pressure and anchor cable, the supporting pile will bend and deform. The maximum bending moment at $2.5 \mathrm{~m}$ below the pit bottom is $1790 \mathrm{kN} \cdot \mathrm{m}$. The bending moment of the anchor cable acting position is negative. The maximum negative bending moment is $1000 \mathrm{kN} \cdot \mathrm{m}$.After the completion of foundation pit excavation, the internal force of retaining pile tends to be stable. It shows the foundation pit is stable as a whole.

(2) It can be seen from the curve in Fig. 7 that the shear force of the pile in the acting area of $2 \sim 6 \mathrm{~m}$ anchor cable is negative and the peak value is $500 \mathrm{kN}$.Anchor cable plays the role of bending deformation resistance. Near $8.5 \mathrm{~m}$ of the pile (bottom of the foundation pit). The shear force reached the maximum value of $716 \mathrm{kN}$. The shear force direction of pile body is opposite to the direction of earth pressure at the position of $11 \mathrm{~m}$ to $14 \mathrm{~m}$.It shows that the pile is anti-sliding under the resistance of soil and soil in this area.

\section{2、Soil pressure}

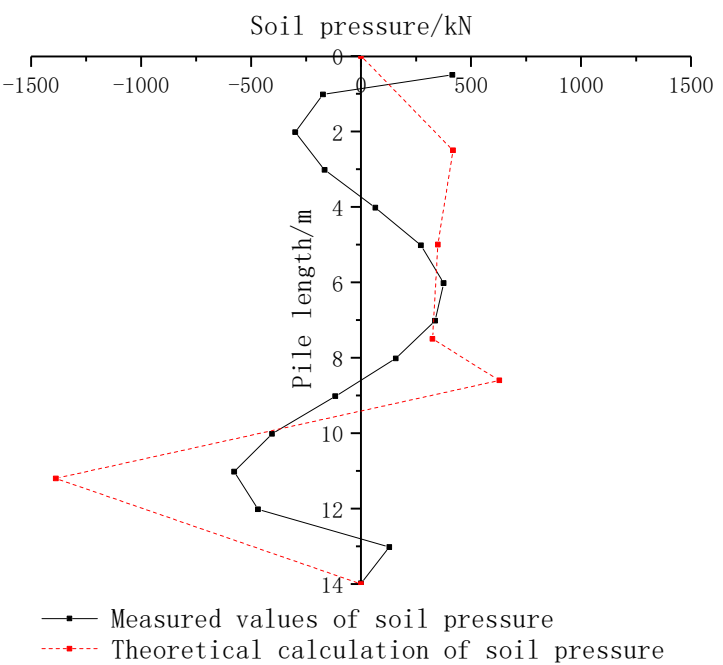

Fig 8 Comparison of measured and theoretical values of earth pressure after excavation

It can be seen from the curve in Fig 8 that the actual earth pressure on the pile and anchor structure after the foundation pit excavation is completed is significantly less than the theoretical value calculated by the classical method. The distribution of earth pressure is characterized by "small upper part and large lower part". There is a big difference between it and the theory, which is mainly affected by the excavation of foundation pit and the action of anchor cable. From the above research and the field measurement in this paper, it is found that there is a deviation in the design of multi-pivot pile anchor structure in the actual situation. There is a big deviation between the classical earth pressure theory and the practice. Classical calculations tend to be too large.

\section{Conclusion}

In this paper, the pile anchor supporting structure of deep foundation pit is taken as the research object. It makes use of the distributed optical fiber sensing technology of BOTDA and back analysis of the stress distribution characteristics of piles to draw the following conclusions:
(1) BOTDA fiber optic sensing technology can accurately obtain the strain at different positions and depths of piles in the pile-anchor retaining structure.It can calculate more in line with the actual situation of the structure.

(2) The test results show that the bending moment at the action position of the anchor cable on the pile anchor structure and $2.5 \mathrm{~m}$ below the bottom of the pit is the maximum.The design should strengthen the structure of such positions to increase the structural strength.

(3) The earth pressure acting on the pile-anchor structure gradually changes from the static earth pressure before excavation to the main dynamic earth pressure. The distribution of earth pressure above the excavation line shows the characteristics of "small upper part and large lower part" after the foundation pit excavation is completed. When there are multiple rows of prestressed anchor cables, the earth pressure applied on the support is less than the calculated value of classical earth pressure theory.

(4) This study takes advantage of the advantages of high anti-interference, high spatial resolution, high precision and distribution of BOTDA technology. It improves the precision of deep foundation pit monitoring to make the monitoring value close to the actual project, which improves the original monitoring system of foundation pit supporting engineering.

\section{Acknowledgments}

The research was funded by the project "Study on the influencing mechanism and control measures of adjacent deep foundation pit development project on structures of the urban rail transit" of Guiyang Urban Rail Transit Group CO.LTD

\section{References}

1. Li Ming,Chen Qichun,Zhao Xin.Application of pile-anchor supporting technology in deep foundation pit engineering $[\mathrm{J}]$.Building Structure; 2020,50(S2).

2. Ravet, F., Bao, X., Zou, L., Yu, Q., Li, Y., Kalosha, V., Chen, L.: Accurate strain detection and localization with the distributed Brillouin sensor based on a phenomenological signal processing approach. In: 13th International Symposium on Smart Structures and Materials and NDE for Health Monitoring and Diagnostics, San Diego, California, United States, 2006, Proceedings of SPIE, Conference vol. 6176: C(1-9).

3. BILlingtON R. Measurement Methods for Stimulated Raman and Brillouin Scattering in Optical Fibres,USA[R]. NPL Report COEM 31. June 1999.

4. THEVENAZ L, NIKLE M, FELLAY A, et a1. Truly distributed strain and temperature sensing using embedded optical fibets[J]. SPIE 5th Annual International Symposium on Smart Structures and Materials,1998,San Diego, California, United States, 
Proceedings of SPIE ,Conference vol.3330: $301-$ 314.

5. WAIT $P$ C, NEWSON $T$ P. Measurement of Brillouin scattering coherence length as a function of pump power to determine Brillouin 1inewidth[J]. Opties Communi- cations, 1995, 117 (1-2) : $142-$ 146.

6. COTTER D. Observation of stimulated Brillouin scattering in low loss silica fibre at $1.33 \mu \mathrm{m}[\mathrm{J}]$. Electronics. Letters., 1982, 18(12): 495 - 496.

7. Suo Wenbing, Chen Gang,Lu Yi.Study on Distributed Monitoring Method of Deep Foundation Pit Retaining Pile Based on the Brillouin Optical Time Domain Technology[J]. Geological Journal of China Universities. 2016,22(04).

8. Yang Zhongping,Liu Yongquan,Liu Xinrong,Xie Yingkun.Excavation Response of the External Loads and Characteristics of Internal Force and Deformation of Anchorage Piles in Foundation Pit. Chinese Journal of Underground Space and Engineering.2016,12(02).

9. Luo Yong,Jiang Bo,Li Chunfeng,Zeng Yao.Research on the Deformation and Internal Force Characteristics of h-type Anti-slide Piles in Landslide Treatment.[J].Chinese Journal of Underground Space and Engineering. 2017,13(06).

10. ZHANG Lei,SHI Bin,ZHANG Dan,HAN Heming,WEI Guangqing.Evaluation and analysis of working state of anti-slide pile with BOTDR technology.[J].Journal of Engineering Geology,2019, 27(6). 